If a junior attempts to avoid a bed crisis by sending home patients for whom in-patient care is indicated and the consultant responsible is not made aware, this distorts the pressure on the service perceived by consultants and managers. It could be postulated that such action by juniors creates an impression of a reduced requirement for beds thus facilitating further mismatch between need and service.

I do not even agree that it is part of the job of a junior doctor to know the bed state. If the decision has been made by a junior to admit a patient then surely it is the job of a designated bed manager to find a bed. If no beds are available then the duty consultant should be asked for advice. It is down to the junior to resist taking responsibility for risky decisions and to pass it back to those with more experience.

MichaEl SHAW, Leighton Hospital, Middlewich Road, Crewe CW1 4QJ

Sir: In response to Frances Foster (Psychiatric Bulletin, June 1994, 18, 371-372) I agree that the current bed shortage throughout the country is cause for concern, not least with junior medical staff.

In addition to the consultant psychiatrist taking fewer risks and delaying discharge, in my experience this has now extended to the Mental Health Review Tribunal who appear increasingly cautious with regard to discharging patients from hospital. This too is exacerbated by lack of finances and facilities available to the social services in the community.

Indeed, despite the policy of closure of many large psychiatric institutions, and even further reduction in the number of available hospital beds and increasing emphasis on community care, the pendulum has begun to swing in the opposite direction. More in-patient facilities will inevitably be needed in the future to accommodate the increasing caution within the field of psychiatry unless this trend ceases.

STEPHEN NOBLETT, Fazakerley Hospital, Liverpool L9 7AL

Sir: We read with interest the letter from Dr Foster concerning bed shortages (Psychiatric Bulletin, June 1994, 18, 371-372). Acute psychiatric beds are becoming an increasingly scarce and precious resource.

We disagree that a reluctance by consultants to discharge patients is the prime cause of such a shortage. There are many other causative factors. Bed closures, inadequate community resources and time spent finding accommodation for the difficult to place chronically mentally ill, combined with a failure to acknowledge their long-term needs, must all play a part.
We agree that bed scarcity does place extra pressures on junior staff, particularly when they are on call. We also experience recurring difficulty in finding vacant beds for patients. This necessitates the risky use of leave beds and even the emergency placement of relatively young patients on psychogeriatric wards. The decision whether or not to admit patients is inevitably influenced by the bed state. Even before assessing patients in the accident and emergency department there can be pressure not to admit them to hospital because of bed shortages and to depend instead on community resources, however inadequate and inappropriate they may be. Risk taking is inevitably devolved to junior staff.

We agree with Turner (Psychiatric Bulletin, 1994, June, 18, 371) that the Mental Health Act does not create an incentive for discharge. The use of acute psychiatric beds for detained or informal patients, while waiting community resources to be identified and funded, is in our view an inappropriate but recurring use of an increasingly scarce resource.

K. SILLIFANT and J. O'DWYER, High Royds Hospital, Menston, Ilkley, Leeds LS9 6AQ

\section{Mental Health Review Tribunals}

Sir: We read with interest the correspondence by Green \& Wallis (Psychiatric Bulletin. June 1994, 18, 374) and Wood (Psychiatric Bulletin. June $1994,18,375)$ regarding attendance of the Responsible Medical Officer at Mental Health Review Tribunals.

The tribunals should not be used to pass the buck'. However, the circumstances in which the RMO may be seen to be doing so vary. For patients detained under section 2 , there is very little time between detention under the Act, applying to the tribunal, the RMO's appraisal and hearing by the tribunal and it would be unwise for the RMO to revoke the Order before the tribunal hearing unless the patient is 'cured' in that short period.

The difficulty arises with patients detained under section 3 and 37 of the Act. The RMO should not wait for an application or a reference to the tribunal to be made before considering the patient's discharge and this should be seriously considered at the time of the renewal of detention, endorsed by hospital managers. One of us (AK) attended 47 tribunals for patients detained under section 3 and 37 under his care over the past four years, not recommending a single discharge and the recommendations were upheld in each case.

The experience of Green \& Wallis cannot be generalised to most psychiatric hospitals because of their highly selective patient group 